\title{
NOTE ON THE MACROANALYSIS OF CARBON AND HYDROGEN BY COMBUSTION
}

\author{
By Donald D. Wagman and Frederick D. Rossini
}

\section{ABSTRACT}

This note describes the present state of the development of an analytical combustion apparatus for the accurate determination, on a macro scale, of carbon and hydrogen in hydrocarbons or in compounds containing carbon, hydrogen, and oxygen. The precision and accuracy attainable are indicated by a report of the results of a series of five experiments performed on highly purified benzoic acid.

\section{CONTENTS}

I. Introduction

II. Apparatus

III. Filling, handling, and weighing the absorption tubes

IV. Experimental procedure for compounds of low volatility

V. Experimental results on purified benzoic acid

VI. References.

\section{INTRODUCTION}

During the past 15 years, several investigations at the National Bureau of Standards have involved precise analyses of carbon and hydrogen $[1,2,3,4,5,6] .^{1}$ Each of these investigations incorporated in its apparatus such prior improvements as were appropriate and made some new contributions to the problem. This note describes the present state of the development of an analytical combustion apparatus for the accurate determination on a macro scale of carbon and hydrogen in hydrocarbons or in compounds containing carbon, hydrogen, and oxygen. The precision and accuracy attainable with this apparatus are indicated by a report of the results of a series of five experiments performed on highly purified benzoic acid.

\section{APPARATUS}

The assembly of the apparatus, as used for nonvolatile liquids or solids, is shown in figure 1 , in which the letters have the following significance: A, cylinder containing oxygen under pressure; $\mathrm{B}$, reducing valve and flow regulator; $\mathrm{C}$, three-way stopcock, Pyrex glass; D, flow meter, Pyrex glass, containing mercury; E, safety trap, Pyrex glass, containing mercury; L, female connection, Pyrex glass, standard taper; F, combustion tube, quartz, containing copper oxide; G, electric heater; W, graded seal, quartz to Pyrex glass; $H$, absorption

\footnotetext{
1 Figures in brackets indicate the literature references at the end of this paper.
} 


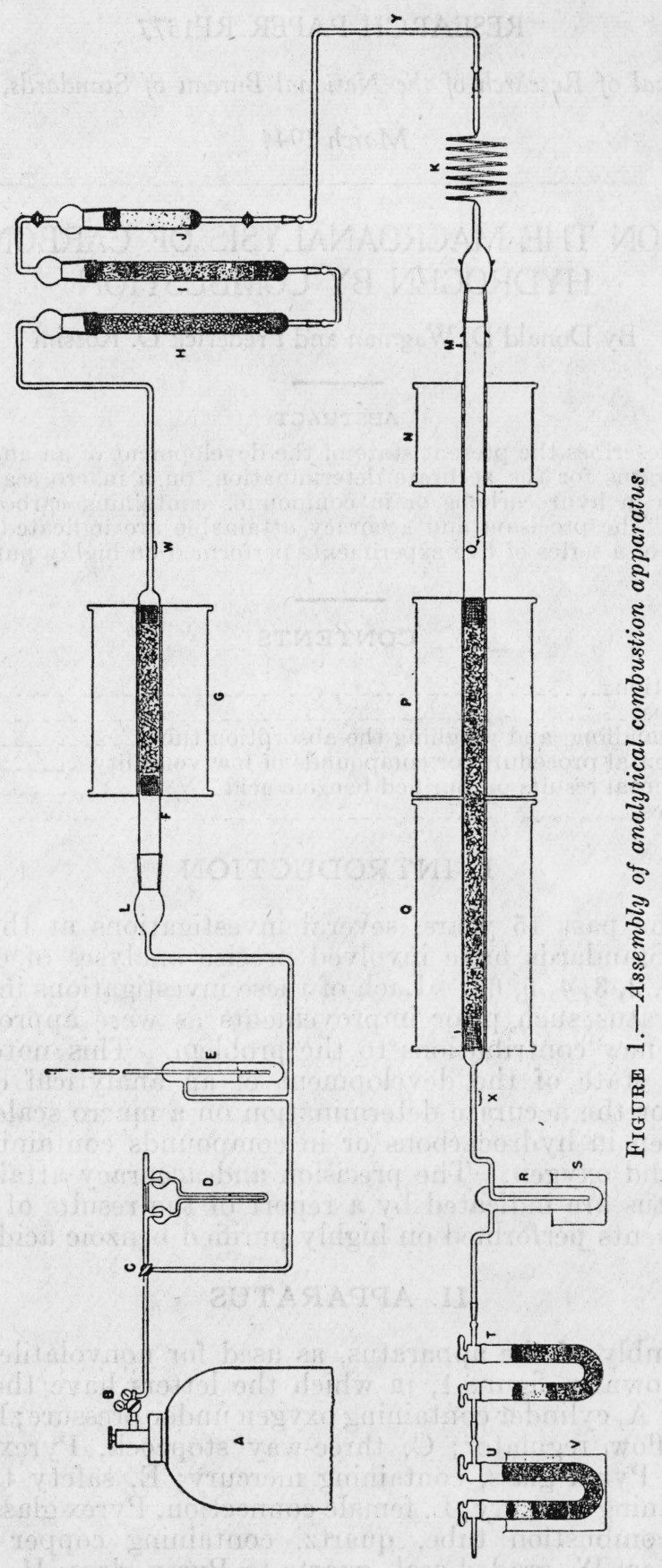


tube, Pyrex glass, containing Ascarite; I, absorption tube, Pyrex glass, containing magnesium perchlorate; $J$, absorption tube, Pyrex glass, bounded by stopcocks, Pyrex glass, containing phosphorus pentoxide; $\mathrm{Y}$, connecting tube, Pyrex glass, stationary; $\mathrm{K}$, connecting tube, Pyrex glass, compressible through the coil, having standard tapered ends as indicated; M, combustion tube, quartz, containing the boat (with sample) and copper oxide, as indicated; $N$, electric heater, for vaporizing sample; $\mathrm{O}$, boat, platinum, containing sample for combustion; $\mathrm{P}, \mathrm{Q}$, electric heaters; X, graded seal, quartz to Pyrex glass; R, trap, Pyrex glass, for temporarily condensing excess water; $\mathrm{S}$, beaker, glass, containing water; T, absorption tube, Pyrex glass, containing, in order, magnesium perchlorate and phosphorus pentoxide, each bounded by a layer of dry asbestos; U, absorption tube, Pyrex glass, containing, in order, Ascarite, magnesium perchlorate, and phosphorus pentoxide, each bounded by a layer of dry asbestos; V, beaker, glass, containing water.

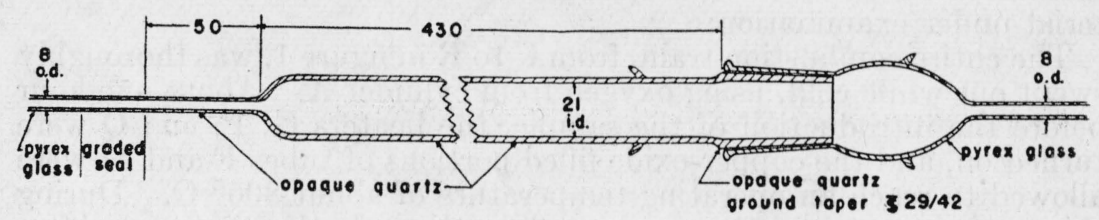

$A$

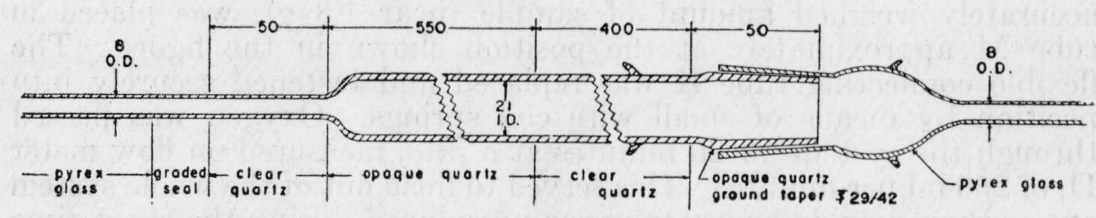

B

FIgURE 2.-Details of the combustion tubes.

$A$, Combustion tube for purification; $B$, main combustion tube. All dimensions in millimeters.

In figure 2 are shown in detail the combustion tubes $\mathrm{F}$ and $\mathrm{M}$, $\mathrm{F}$ being the combustion tube for purification of the oxygen and $\mathrm{M}$ that for the main reaction of combustion.

\section{FILLING, HANDLING, AND WEIGHING THE ABSORP- TION TUBES}

The manner of filling, handling, and weighing the absorption tubes, and of calculating the true masses of water and carbon dioxide absorbed, is described on pages 6 to 9 and 39 to 41 of reference [2]. With the absorption tubes flushed with water-free and carbon dioxidefree hydrogen just prior to each weighing, and with a duplicate closed absorption tube being used as a counterpoise, the mass of water is

$$
m\left(\mathrm{H}_{2} \mathrm{O}\right)=0.99991(\Delta m) \text {, }
$$

and the mass of carbon dioxide is

$$
m\left(\mathrm{CO}_{2}\right)=0.99990(\Delta m),
$$


where $\Delta m$ is the apparent increase in mass of the corresponding absorption tube, using brass weights. The numerical factors in eq 1 and 2 include both the buoyant effect of the air on the brass weights and the effect of the change in volume of the solid phase (and consequently of the gas phase) in the absorption tube during the absorption process.

It is important to note the necessity of performing "blank" experiments on each operation which may add to or subtract from the mass of sample, of water, or of carbon dioxide, as described in section V.

The balance and weights, the weighing procedure, and the lubricant employed on the stopcocks and other ground joints, etc., are discussed in the earlier papers to which reference has already been made.

\section{EXPERIMENTAL PROCEDURE FOR COMPOUNDS OF LOW VOLATILITY}

The experimental procedure for compounds of low volatility is illustrated by the following operations with benzoic acid as the material under examination:

The entire combustion train, from $\mathrm{C}$ to $\mathrm{R}$ in figure 1, was thoroughly swept out while cold, using oxygen from cylinder A. About one hour before the introduction of the sample, the heaters $\mathrm{G}, \mathrm{P}$, and $\mathrm{Q}$ were turned on, and the copper-oxide filled portions of tubes $\mathrm{F}$ and $\mathrm{M}$ were allowed to reach an operating temperature of about $800^{\circ} \mathrm{C}$. During this period, oxygen continued to flow through the system. After combustion tubes $\mathrm{F}$ and $\mathrm{M}$ had attained their operating temperature, the train was opened at $\mathrm{K}$ and a platinum boat, $\mathrm{O}$, containing an accurately weighed amount of sample (near $1.8 \mathrm{~g}$ ), was placed in tube $M$ approximately at the position shown in the figure. The flexible connecting tube $\mathrm{K}$ was replaced and fastened securely into position by means of small wire coil springs. Oxygen was passed through the system for 20 minutes at a rate, measured on flow meter $\mathrm{D}$, of $250 \mathrm{ml}$ per minute. This served to flush out of the whole system any carbon dioxide or water vapor introduced during the short time the train was open for the introduction of the sample. This procedure may be used only for compounds that are sufficiently nonvolatile or very pure, so that no appreciable fractionation of the sample can occur during this flushing period. Following this flushingout process, the weighed absorption tubes $T$ and $U$ were connected in series with trap $R$, as shown in figure 1 . Tube $T$ contained anhydrous magnesium perchlorate backed with phosphorus pentoxide, each layer of absorbent being bounded with dry asbestos. Tube U contained, in order, Ascarite (commercial mixture of sodium hydroxide and asbestos), anhydrous magnesium perchlorate, and phosphorus pentoxide, each bounded with dry asbestos. To absorb the heat evolved by the reaction of carbon dioxide with the Ascarite, tube U was kept immersed in a beaker of cold distilled water.

With the oxygen still flowing through the system at a rate of $250 \mathrm{ml}$ per minute, heater $\mathrm{N}$ was turned on slowly to reach an operating temperature of about $180^{\circ} \mathrm{C}$, at which temperature benzoic acid has a vapor pressure of the order of $80 \mathrm{~mm} \mathrm{Hg}$. After combustion had begun, as evidenced by the condensation of water in tube $R$, the exposed parts of combustion tube $M$, between heaters $N$ and $P$, were covered with appropriately shaped blocks of magnesia insulation. The combustion then proceeded smoothly to the end, requiring about $2 \frac{1}{2}$ hours for the actual combustion. 
When the reaction was complete, the flow of oxygen was increased to about $400 \mathrm{ml}$ per minute and allowed to run for 4 hours. If necessary, to facilitate the evaporation of the water condensed in trap $R$, the cold water in beaker $S$ was replaced with warm water. At the end of this period all of the water and carbon dioxide formed in the combustion was in the absorption tubes $T$ and $U$, respectively. The oxygen was turned to waste at stopcock $\mathrm{C}$, absorption tubes $\mathrm{T}$ and $U$ were closed to each other and to the atmosphere and removed from the train, and the train was capped at the exit end of trap $R$ until the next experiment.

The absorption tubes were handled as mentioned in the preceding section, the lubricant being removed from the end connecting joints with ether. The tubes were then flushed for 10 minutes with waterfree and carbon-dioxide-free hydrogen and placed in the balance ease. About 30 minutes was allowed for the tubes to come to equilibrium in the balance case before weighing them. The weighing, and reduction of the data to obtain the true masses of water and carbon dioxide absorbed, was performed as described in the preceding section.

"Blank" experiments were performed as follows:

(a) To determine the mass of benzoic acid lost from the sample during the flushing of the train after the sample was introduced but before heater $\mathrm{N}$ was turned on.

(b) To determine the increase in weight of the absorption tubes with all operating conditions the same as in a regular combustion experiment except that no benzoic acid was introduced, the train being opened at $\mathrm{K}$ as usual, however.

\section{EXPERIMENTAL RESULTS ON PURIFIED BENZOIC ACID}

The experimental results obtained on purified benzoic acid, using the apparatus and procedure described in the preceding sections, are reported in tables 1 and 2 . The benzoic acid used was from a lot of NBS Standard Sample 39f, which had been further purified to serve as a standard for microanalysis. According to the certificate of analysis for NBS Standard Sample 39f, "freezing point measurements indicate a mole percent purity of 99.98 " and "on the basis of titration a purity of 100.03 percent is indicated." Since the small amount of impurity will be similar to the parent substance, it is likely to have an insignificant effect on the content of carbon and hydrogen

TABLE 1.-Results of experiments to determine the change in mass of the absorption tubes, with operating conditions as in a regular combustion experiment, except that no benzoic acid was burned

\begin{tabular}{|c|c|c|c|}
\hline Experiment number & $\begin{array}{l}\text { Volume } \\
\text { of oxygen }\end{array}$ & $\begin{array}{l}\text { Increase in } \\
\text { mass of ab- } \\
\text { sorption tube } \\
\text { for water }\end{array}$ & $\begin{array}{l}\text { Increase in } \\
\text { mass of ab- } \\
\text { sorption tube } \\
\text { for carbon } \\
\text { dioxide }\end{array}$ \\
\hline $\begin{array}{l}1 \\
2 \ldots \\
3 \ldots\end{array}$ & $\begin{array}{c}\text { Liters } \\
120 \\
120 \\
130\end{array}$ & $\begin{array}{l}g \\
0.00020 \\
.00070 \\
.00035\end{array}$ & $\begin{array}{l}g \\
0.00023 \\
.00025 \\
.00043\end{array}$ \\
\hline $\begin{array}{l}\text { Mean } \\
\text { Standard deviation of } \\
\text { the mean }\end{array}$ & 123 & $\begin{array}{r}0.00042 \\
\pm 0.00015\end{array}$ & $\begin{array}{r}0.00030 \\
\pm 0.00006\end{array}$ \\
\hline
\end{tabular}

$672139-44-4$ 


\section{Journal of Research of the National Bureau of Standards}

in the sample. The actual sample used in the present investigation was found to contain $0.0018 \pm 0.0004$ percent by weight of water [8].

The results of four experiments to determine the mass of benzoic acid lost in the flushing operation after introduction of the sample, with a flow of oxygen of $250 \mathrm{ml}$ per minute for 15 minutes, gave a mean value of $0.00005 \mathrm{~g}$, with a standard deviation of the mean equal to $\pm 0.00001 \mathrm{~g}$. Since the flushing operation in the actual experiments involved a flow of oxygen at the rate of $250 \mathrm{ml}$ per minute for 20 minutes, the correction applied in the actual experiments was $20 / 15$ of the mean of the four experiments.

TABLE 2.-Results on benzoic acid

\begin{tabular}{|c|c|c|c|c|c|}
\hline $\begin{array}{l}\text { Number } \\
\text { of experi- } \\
\text { ments }\end{array}$ & $\begin{array}{l}\text { Mean mass } \\
\text { of sample a }\end{array}$ & $\begin{array}{l}\text { Mean mass } \\
\text { of carbon } \\
\text { dioxide b }\end{array}$ & $\begin{array}{c}\text { Mean mass } \\
\text { of water }{ }^{\circ}\end{array}$ & $\begin{array}{l}\text { Carbon in sample d } \\
\text { (percentage by } \\
\text { weight) }\end{array}$ & $\begin{array}{l}\text { Hydrogen in sam- } \\
\text { ple d (percentage } \\
\text { by weight) }\end{array}$ \\
\hline 5 & $\begin{array}{c}g \\
1.84358\end{array}$ & 4. 56040 & $\begin{array}{c}g \\
0.81628\end{array}$ & 68. 8367 & 4. $9546_{1}$ \\
\hline \multicolumn{4}{|c|}{$\begin{array}{l}\text { Standard deviation of the mean } \\
\text { Theoretical value d }\end{array}$} & $\begin{array}{c} \pm 0.001_{3} \\
68.843\end{array}$ & $\begin{array}{r} \pm 0.0010 \\
4.9526\end{array}$ \\
\hline \multicolumn{4}{|c|}{ Experimental value minus theoretical value...... } & $-0.006 \pm 0.003 e$ & $+0.0020 \pm 0.0028$ \\
\hline
\end{tabular}

a Corrected by a "blank" of $0.00006 \mathrm{~g}$ and for $0.0018 \pm 0.0004$ percent by weight of water in the original sample. (See text.)

b Corrected by a "blank", of $0.00035 \mathrm{~g}$. (See text and table 1.)

e Corrected by a "blank" of $0.00049 \mathrm{~g}$ and for $0.0018 \pm 0.0004$ percent by weight of water in the original sample. (See text and table 1.)

d Calculated using the following atomic weights: 0 , 16.0900; H, 1.0080; C, 12.010.

- The uncertainty assigned here is twice the over-all standard deviation [7], including the standard deviations of the "blank" experiments. (See text and tables 1 and 2.)

Table 1 gives the results of three experiments to determine the increase in weight of the absorption tubes when no benzoic acid was burned, all other conditions being the same as in an actual experiment. It was found that the volume of oxygen that flowed through the train was $162,145,129,145$, and 136 liters, respectively, in the five experiments, with a mean value of 143 liters. The means of the values in table 1 were therefore multiplied by the factor of $143 / 123$ to give the proper "blank" correction to be applied to the observed increases in mass of the two absorption tubes.

Table 2 gives the mean of the experimental results of a series of five combustion experiments with benzoic acid, with the masses of sample, water absorbed, and carbon dioxide absorbed being obtained by applying the appropriate blank corrections to the respective observed differences in weight, together with a comparison of the experimental results with the theoretical values for benzoic acid.

\section{REFERENCES}

[1] E. W. Washburn, J. H. Bruun, and M. M. Hicks, BS J. Research 2, 467 (1929) RP45.

[2] F. D. Rossini, BS J. Research 6, 1, 37 (1931) RP259, RP260.

[3] F. D. Rossini, BS J. Research 8, 119 (1932) RP405.

[4] W. H. Smith, C. P. Saylor, and H. J. Wing, BS J. Research 10, 479 (1933) RP544.

[5] B. J. Mair and C. B. Willingham, J. Research NBS 21, 535 (1938) RP1143.

[6] V. R. Deitz and L. F. Gleysteen, J. Research NBS 28, 795 (1942) RP1479.

[7] F. D. Rossini and W. E. Deming, J. Wash. Acad. Sci. 29, 416 (1939).

[8] F. W.Schwab and E. Wichers, unpublished data, National Bureau of Standards.

Washington, January 11, 1944. 